\title{
Degradation Effect of Sulfa Antibiotics by Potassium Ferrate Combined with Ultrasound (Fe(VI)-US)
}

\author{
Kejia Zhang, ${ }^{1,2}$ Zhang Luo, ${ }^{1,2}$ Tuqiao Zhang, ${ }^{1,2}$ Naiyun Gao, ${ }^{3}$ and Yan $\mathrm{Ma}^{3,4}$ \\ ${ }^{1}$ College of Civil Engineering and Architecture, Zhejiang University, Hangzhou 310058, China \\ ${ }^{2}$ Key Laboratory of Drinking Water Safety and Distribution Technology of Zhejiang Province, Zhejiang University, \\ Hangzhou 310058, China \\ ${ }^{3}$ State Key Laboratory of Pollution Control and Resource Reuse, Tongji University, Shanghai 200092, China \\ ${ }^{4}$ Shanghai Urban Water Resources Development and Utilization National Engineering Center Co. Ltd., Shanghai 200082, China \\ Correspondence should be addressed to Naiyun Gao; gaonaiyun1@126.com and Yan Ma; my041203@126.com
}

Received 5 February 2015; Accepted 21 March 2015

Academic Editor: Jie Fu

Copyright (C) 2015 Kejia Zhang et al. This is an open access article distributed under the Creative Commons Attribution License, which permits unrestricted use, distribution, and reproduction in any medium, provided the original work is properly cited.

\begin{abstract}
Sulfa antibiotics are a family of typical broad-spectrum antibiotics, which have become one of the most frequently detected antibiotics in water, posing a great threat to human health and ecosystem. Potassium ferrate is a new type of high-efficiency multifunctional water treatment agent, collecting the effects of oxidation, adsorption, flocculation, coagulation, sterilization, and deodorization. Performance and mechanism of degradation of typical broad-spectrum antibiotics by Fe(VI)-US were further studied, investigating the degradation effect of sulfa antibiotics by single ultrasound, single potassium ferrate, and potassium ferrate-ultrasound ( $\mathrm{Fe}(\mathrm{VI})$-US). It was found that $\mathrm{Fe}(\mathrm{VI})$-US technology had a significant role in promoting the degradation of sulfa antibiotics via orthogonal experiments. Factors evaluated included sulfa antibiotics type, $\mathrm{pH}$ value, potassium ferrate dosage, ultrasonic frequency, and ultrasonic power, with the $\mathrm{pH}$ value and potassium ferrate dosage being affected most significantly. One reason for synergy facilitating the degradation is the common oxidation of potassium ferrate and ultrasound, and the other is that $\mathrm{Fe}(\mathrm{III})$ produced promotes the degradation rate. According to the product analysis and degradation pathways of three sulfa antibiotics, ferrate-sonication sulfa antibiotics are removed by hydroxyl radical oxidation.
\end{abstract}

\section{Introduction}

Due to the toxicity of antibiotics and their wide usage and even abuse in the treatment of human and poultry, beasts of infectious diseases, antibiotics, have become a hot issue in water treatment nowadays. Recently, a certain concentration of antibiotic residues has been detected in surface water, groundwater, drinking water, sludge and soil, and some other environmental media $[1,2]$. Ninety kinds of organic pollutants were detected in 139 rivers from more than 30 states of USA, including pesticides, pharmaceuticals, veterinary drugs, and hormones [3]. Samples were taken from the 7 sites and 15 substations of agricultural watershed of the USA, and the existence of antibiotics in water samples was measured [4]. A certain concentration of antibiotics was detected in municipal wastewater, farmland soil, surface water, and even drinking water in Germany [5]. It was found that they contained high concentration of antibiotics in the sediments of fish farming area of Wujiangdu reservoir (China), with chloramphenicol (CAP) $5-37 \mu \mathrm{g} \cdot \mathrm{kg}^{-1}$, oxytetracycline (OTC) $21-156 \mu \mathrm{g} \cdot \mathrm{kg}^{-1}$, tetracycline (TC) $84-$ $248 \mu \mathrm{g} \cdot \mathrm{kg}^{-1}$, and chlortetracycline (CTC) $42-90 \mu \mathrm{g} \cdot \mathrm{kg}^{-1}$ [6]. In Guiyang (China), antibiotics were also found in city life sewage, with CAP $1.8-4.3 \mu \mathrm{g} \cdot \mathrm{L}^{-1}$, OTC 5-8 $\mu \mathrm{g} \cdot \mathrm{L}^{-1}$, TC $4.4-$ $10 \mu \mathrm{g} \cdot \mathrm{L}^{-1}$, and CTC $0-2.2 \mu \mathrm{g} \cdot \mathrm{L}^{-1}$.

As typical broad-spectrum antibiotics, sulfa antibiotics are commonly used in clinical treatment, animal husbandry, and aquaculture. With the rapid development of Chinese animal husbandry, the usage of sulfa antibiotics as veterinary drugs and fishery drugs increased. Some studies analyzed the content and distribution of four kinds of sulfa antibiotics in 
the dung of 20 scale farms in Guangdong province (China); the results showed that sulfa compounds in dung was 1925.9$13399.5 \mu \mathrm{g} \cdot \mathrm{kg}^{-1}$, mainly sulfamerazine and sulfamethoxazole. Sulfa antibiotics detection rate in cow dung was more than $90 \%$, the content of which was $1039.4-15930.3 \mu \mathrm{g} \cdot \mathrm{kg}^{-1}$, mainly sulfamethoxazole and sulfamerazine [7]. Sulfa antibiotics in farm manure discharged into waters with rainwater runoff and farm wastewater in abundance, which have become one of the most frequently detected antibiotics in water, and their distributions in the environment were not optimistic [3]. From 2006 to 2007, 19 water companies in USA detected raw water, treated water, and pipeline water, the most commonly detected compounds reached up to 11 kinds, and sulfa antibiotics (sulfamethoxazole) was one of them [8]. Twenty-two kinds of antibiotics were detected in the lake of Baiyangdian (China), among which sulfa antibiotics were the most widely distributed and were of the highest levels; the concentration reached $0.86-1563 \mathrm{ng} \cdot \mathrm{L}^{-1}$ [9]. China's Pearl River Basin was studied by $\mathrm{Xu}$ [10], which included the residue of antibiotics both in Guangzhou and Shenzhen rivers, the content of sulfamethoxazole in Shenzhen river reaching $880 \mathrm{ng} \cdot \mathrm{L}^{-1}$. Typical broad-spectrum sulfa antibiotics can be detected both in surface water and drinking water all over the world, which not only explains the serious material pollution now but also declares the fact that the conventional treatment process cannot remove sulfa antibiotics effectively. Fortunately, more and more attention has been given to the research of degradation of antibiotics in water environment. Generally speaking, there are physical, chemical, and biological treatment methods for the removal of antibiotics in wastewaters; all these methods can remove antibiotics effectively with high concentration of antibiotics. However, these methods cannot work well for drinking water sources with low levels of antibiotics. Therefore, much more energy should be devoted to study of the degradation of sulfa antibiotics in order to find out effective control methods, improving water quantity and ensuring water security.

The German chemical and physicist Georg Stahl first discovered and reported the ferrate in 1702; since then, the international research of ferrate has never stopped. In recent years, potassium ferrate has gained widespread attention in the field of water treatment for its strong oxidation. It is hexavalent $(\mathrm{Fe}(\mathrm{VI}))$ for iron element of potassium ferrate; potassium ferrate exists in the form of $\mathrm{FeO}_{4}{ }^{2-}$ in aqueous solution, having extremely strong oxidizing with redox potential $+2.20 \mathrm{~V}$ and $+0.72 \mathrm{~V}$, respectively, in acidic and alkaline conditions [11]. Potassium ferrate have strong oxidizing under acid condition, the oxidation of which is much stronger than the common water treatment disinfectants such as chlorine, ozone, hydrogen peroxide, and chlorine dioxide [12].

Potassium ferrate oxidation has a strong selectivity for pollutants, and the oxidation rate and efficiency in different compounds are different. The removal rate of some refractory organics is not high when potassium ferrate is used alone, and potassium ferrate itself is easily decomposed at low $\mathrm{pH}$ value, affecting its oxidation efficiency. Therefore, there is a need to research potassium ferrate coupling technique for achieving better treatment effect. Potassium ferrate coupling technique is a hot topic and application direction in the study of potassium ferrate; the existing techniques mainly include potassium ferrate-aluminium, potassium ferrate-ozone, and potassium ferrate-photocatalysis.

This study took the typical broad-spectrum sulfa antibiotics as target pollutants, removed by $\mathrm{Fe}(\mathrm{VI})$-US oxidation, studying different impacts of degradation effect of sulfadiazine, establishing the reaction kinetics model, investigating the degradation mechanism of sulfa antibiotics, and providing certain theoretical basis and technical support for drugs polluted water treatment.

\section{Materials and Methods}

2.1. Chemicals. Sulfadiazine (purity $>99 \%$ ), sulfamerazine (purity > 99\%), and sulfamethoxazole (purity > 99\%) were all purchased from Sigma-Aldrich (USA); their physical and chemical properties (molecular formula, structural formula, molecular weight, ionization equilibrium constant $\mathrm{pKa}$, etc.) were shown in Table 1. Oxidant potassium ferrate (purity > 90\%) was also purchased from Sigma-Aldrich (USA). Buffer solution used in the experiment was made up of analytical grade of potassium hydroxide, dipotassium hydrogen phosphate, potassium dihydrogen phosphate, and potassium borate, with sodium thiosulfate being reaction terminators. Mobile phases of formic acid purchased from Fluka (Switzerland) and acetonitrile purchased from Sigma-Aldrich (USA) are chromatographic grade; formic acid solution was prepared from Milli-Q ultrapure water (18.2 $\Omega$ ). Other chemicals were of analytical grade and above, and all were purchased from Sinopharm Chemical Reagent Co., Ltd. Water used in experiment was deionized water.

\subsection{Experimental Apparatus and Methods}

2.2.1. Apparatus and Methods of Ferrate Oxidation. Degradation of sulfa antibiotics by $\mathrm{Fe}(\mathrm{VI})$ took place in $150 \mathrm{~mL}$ conical flask. The $\mathrm{pH}$ value of reaction solution was adjusted by buffer solution; add a certain amount of $\mathrm{Fe}(\mathrm{VI})$ into the reaction solution under the condition of magnetic stirring, take samples at scheduled time, and then add a small amount of $0.1 \mathrm{~mol} \cdot \mathrm{L}^{-1}$ sodium thiosulfate to terminate the reaction. Samples taken were analyzed after centrifugation at $6000 \mathrm{r} / \mathrm{min}$ for $10 \mathrm{~min}$; all experiments were performed at room temperature $\left(25 \pm 2^{\circ} \mathrm{C}\right)$.

2.2.2. Apparatus and Methods of Ultrasonic Reaction. Ultrasonic reactor used was purchased from Shanghai Poly Fiber Ultrasound Equipment Co., Ltd., consisting of ultrasonic generator, ultrasonic transducer, and reaction vessel. There are four ultrasonic generators; the models are, respectively, HF-200 (ultrasonic frequency $f=223 \mathrm{kHz}$ ), HF-400 $(f=$ $400 \mathrm{kHz}), \mathrm{HF}-600(f=600 \mathrm{kHz})$, and HF-800 $(f=800 \mathrm{kHz})$; ultrasonic power can be adjusted ranging from 30 to $100 \mathrm{~W}$, with maximum power density $3 \mathrm{~W} \cdot \mathrm{cm}^{-2}$. Ultrasonic reaction was conducted in an open stainless steel cylinder (inner 
TABLE 1: The physical and chemical properties of standards.

\begin{tabular}{|c|c|c|c|c|c|}
\hline \multirow{2}{*}{ Substance name } & \multirow{2}{*}{ Formula } & \multirow{2}{*}{ Structure } & \multirow{2}{*}{ Molecular weight/Da. } & \multicolumn{2}{|c|}{$\mathrm{pK}_{a}$} \\
\hline & & & & $\mathrm{pK}_{a 1}$ & $\mathrm{pK}_{a 2}$ \\
\hline Sulfadiazine & $\mathrm{C}_{10} \mathrm{H}_{10} \mathrm{~N}_{4} \mathrm{O}_{2} \mathrm{~S}$ & $\mathrm{O}$ & 250.27 & 2.49 & 6.50 \\
\hline Sulfamerazine & $\mathrm{C}_{11} \mathrm{H}_{12} \mathrm{~N}_{4} \mathrm{O}_{2} \mathrm{~S}$ & $\mathrm{O}$ & 264.30 & - & 7.00 \\
\hline Sulfamethoxazole & $\mathrm{C}_{10} \mathrm{H}_{11} \mathrm{~N}_{3} \mathrm{O}_{3} \mathrm{~S}$ & $\stackrel{\Pi}{\mathrm{O}}$ & 253.28 & 1.74 & 5.70 \\
\hline
\end{tabular}

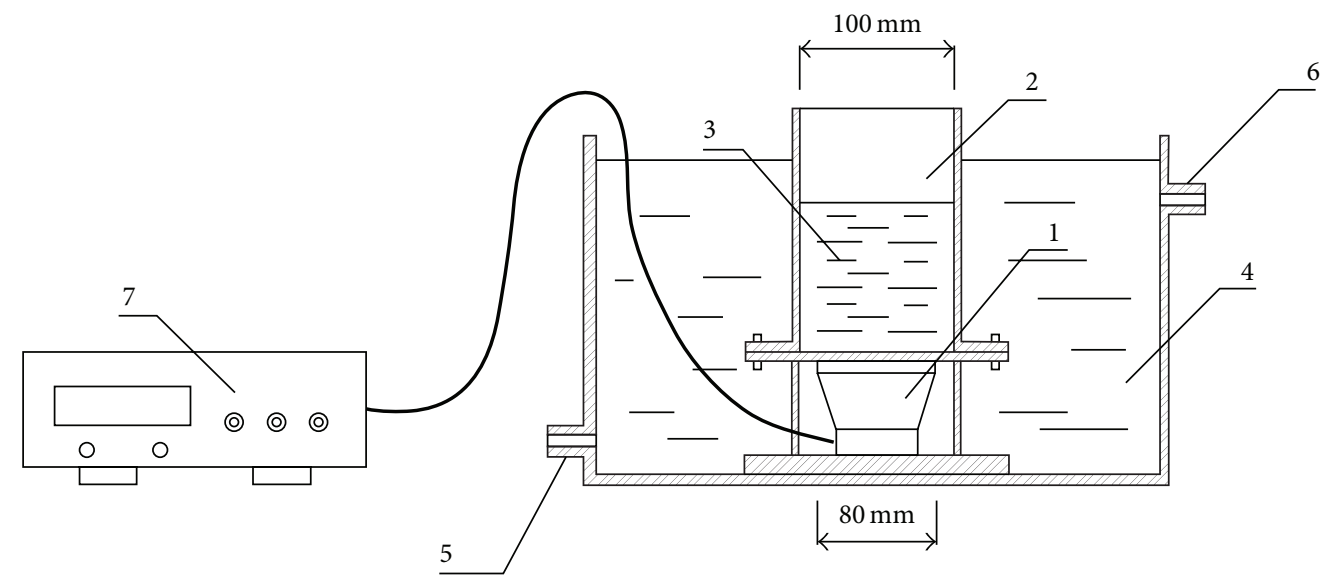
(1) Ultrasonic transducer
(5) Cooling water inlet
(2) Stainless steel reactor
(6) Cooling water outlet
(3) Water samples
(7) Ultrasonic generator

(4) Water bath

FIGURE 1: Schematic diagram of ultrasonic apparatus.

diameter $\Phi=10.0 \mathrm{~cm}, H=10.0 \mathrm{~cm}$ ), the bottom of the cylinder was directly connected with the ultrasound transducer, and the joints were sealed with PTFE O-ring. Stainless steel cylinder was placed in a thermostatic water bath system (Figure 1), with the reaction temperature controlled at $25 \pm$ $2{ }^{\circ} \mathrm{C}$.

The volume of reaction solution was $100 \mathrm{~mL}$ in all experiments, and the $\mathrm{pH}$ value was adjusted by buffer solution. Reaction was conducted in the stainless steel reactor, and the samples were collected at predetermined time intervals for the analysis of sulfa antibiotics. When performing Fe(VI)US samples taken should be added to a small amount of
$0.1 \mathrm{~mol} \cdot \mathrm{L}^{-1}$ sodium thiosulfate to terminate reaction, with the samples being analyzed after centrifugation.

\subsection{Analytical Methods and Detecting Instrument}

2.3.1. Detection of $\mathrm{Fe}(\mathrm{VI})$ Concentration. $\mathrm{Fe}(\mathrm{VI})$ exists in the form of $\mathrm{FeO}_{4}{ }^{2-}$ when dissolved in water; the solution is purple, with a clear UV-visible spectrum; the absorption curve has been shown in appropriate concentration range $(1.41 \times$ $\left.10^{-5}-5.05 \times 10^{-4} \mathrm{~mol} \cdot \mathrm{L}^{-1}\right)[13]$; there is a linear relationship between concentration and absorbance of $\mathrm{Fe}(\mathrm{VI})$ solution; thus, the corresponding concentration can be obtained by 


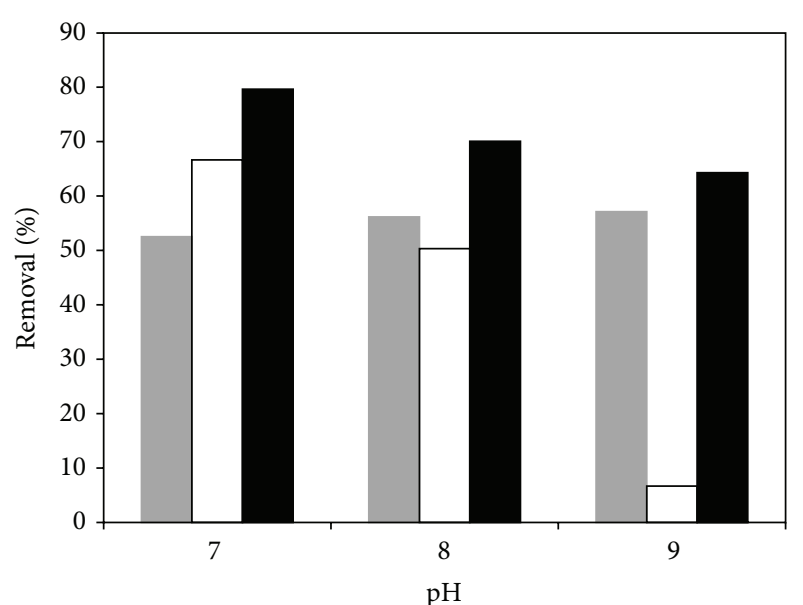

(a) $\mathrm{SD}$

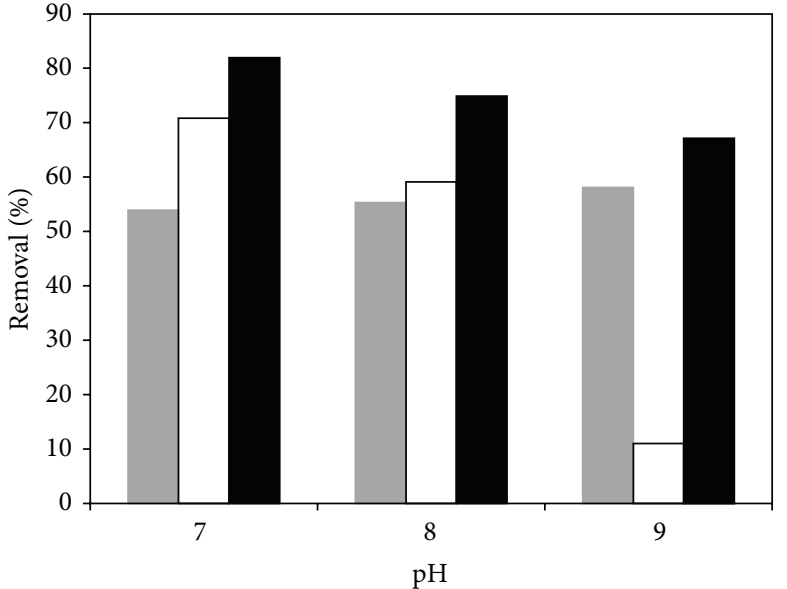

(b) $\mathrm{SM}$

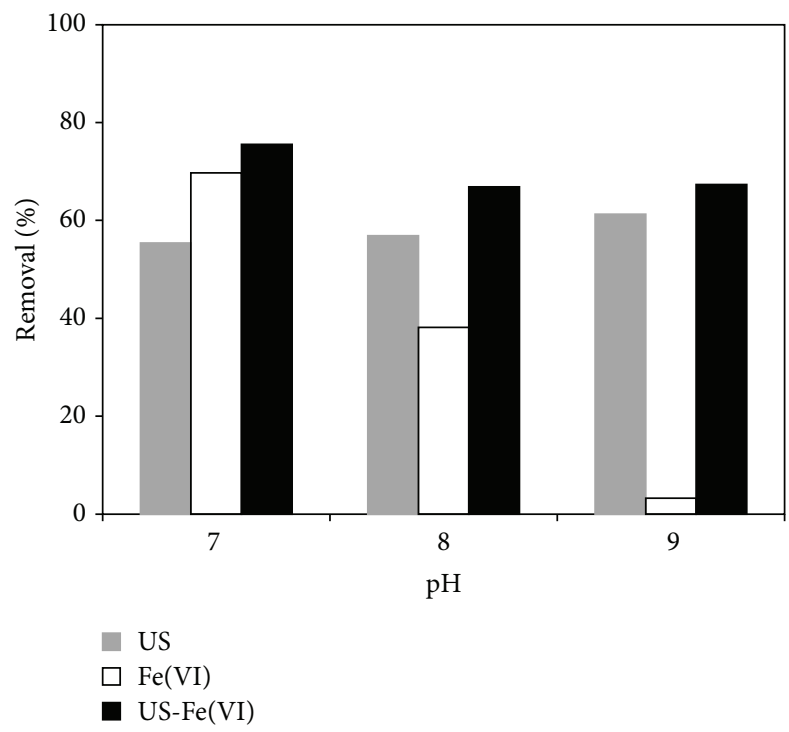

(c) SMX

FIGURE 2: The removal effect of sulfa antibiotics oxidized by Fe(VI)-US: (a) sulfadiazine; (b) sulfamerazine; (c) sulfamethoxazole.

measuring the absorbance of $\mathrm{Fe}(\mathrm{VI})$ solution. In experiment, absorbance of $\mathrm{Fe}(\mathrm{VI})$ solution was measured by UV/VIS spectrophotometer instrument; the concentration was calculated according to Bill-Lambert's law as follows:

$$
A=\varepsilon b c,
$$

where $\varepsilon$ is molar absorption coefficient, reflecting the solution absorption capacity of a wavelength of light, $\mathrm{L} \cdot \mathrm{mol}^{-1} \cdot \mathrm{cm}^{-1} ; b$ is cuvette width, $\mathrm{cm} ; c$ is analyte concentration, $\mathrm{mol} \cdot \mathrm{L}^{-1}$.

When cuvette width $b$ is $1 \mathrm{~cm}$, Bill Lambert's law is expressed in

$$
A=\varepsilon \mathcal{c} .
$$

Absorbance of $0.25 \mathrm{mmol} \cdot \mathrm{L}^{-1}$ and $0.51 \mathrm{mmol} \cdot \mathrm{L}^{-1}$ of potassium ferrate solution reached maximum at $510 \mathrm{~nm}$ wavelength. At the same time, it was documented that reaction products $\mathrm{Fe}(\mathrm{II})$ and $\mathrm{Fe}$ (III) phosphate would not interfere with the detection at $510 \mathrm{~nm}$ wavelength; thus, we can accurately track the Fe(VI) concentration change and adopt the wavelength of $510 \mathrm{~nm}$ as the determination of $\mathrm{Fe}(\mathrm{VI})$ solution [14]. Molar absorption coefficient of Fe(VI) solution is $1150 \mathrm{M}^{-1} \cdot \mathrm{cm}^{-1}$ at $510 \mathrm{~nm}$ wavelength [15]. In addition, due to the $\mathrm{Fe}(\mathrm{VI})$ easily decomposed to $\mathrm{Fe}(\mathrm{OH})_{3}$, interfering with the detection results, samples were measured after centrifugation at $6000 \mathrm{r} \cdot \mathrm{min}^{-1}$ for $10 \mathrm{~min}$, and the supernatant was taken for spectrophotometry.

2.3.2. Detection of Three Kinds of Sulfa Antibiotics by HPLC. High performance liquid chromatography (HPLC) was adopted on three kinds of sulfa antibiotics for quantitative analysis. The concentrations of sulfadiazine, sulfamerazine, and sulfamethoxazole were measured by Waters e2695-2489 


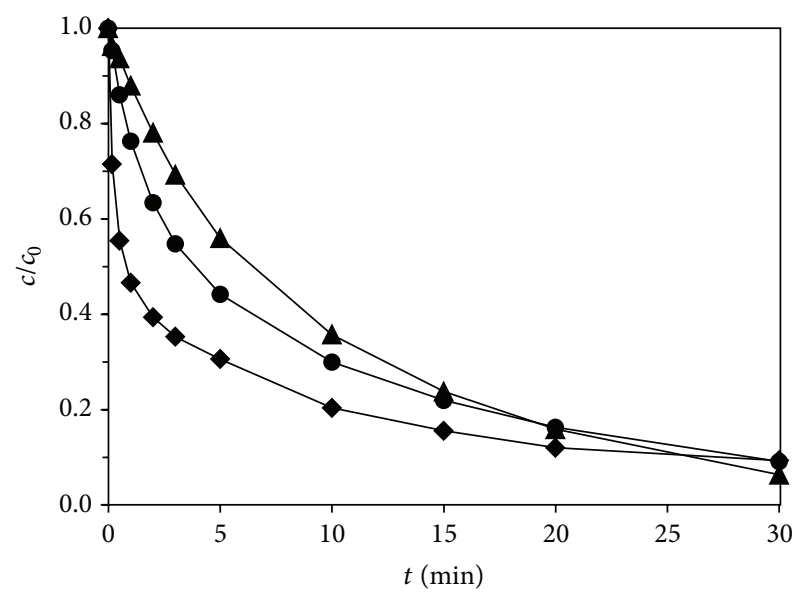

(a) SD

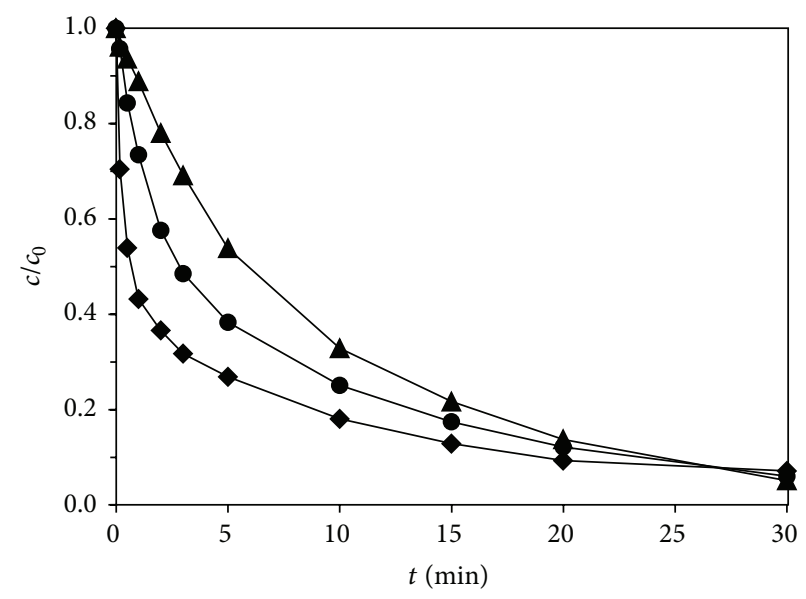

(b) SM

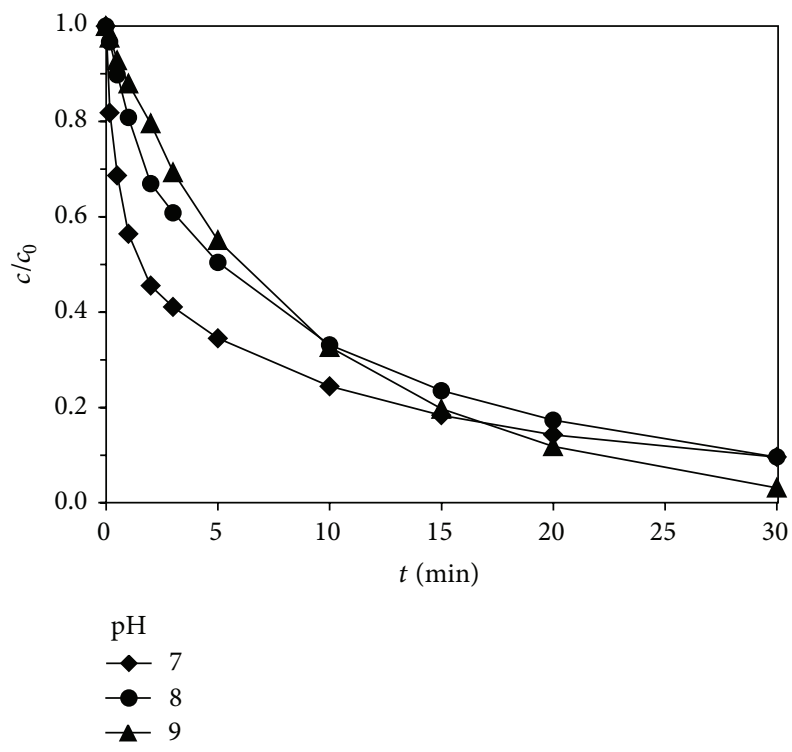

(c) SMX

FIGURE 3: Effect of $\mathrm{pH}$ values on degradation of sulfa antibiotics by Fe(VI)-US: (a) sulfadiazine; (b) sulfamerazine; (c) sulfamethoxazole.

HPLC (UV detector) and Waters Symmetry C18 column to column $(250 \mathrm{~mm} \times 4.6 \mathrm{~mm})$. Acetonitrile and mass fraction of $0.1 \%$ formic acid solution, the volume ratio of $40: 60$, were adopted for mobile phase, with flow rate $0.8 \mathrm{~mL} \cdot \mathrm{min}^{-1}$, column temperature $35^{\circ} \mathrm{C}$, and detection wavelength $270 \mathrm{~nm}$. Under these conditions, sulfadiazine, sulfamerazine, and sulfamethoxazole peaked well and the peak time was $4.081 \mathrm{~min}$, $4.429 \mathrm{~min}$, and $6.015 \mathrm{~min}$, respectively.

2.3.3. Detection of Three Kinds of Sulfa Antibiotics and Their Degradation Product by LC-MS-MS. HPLC-MS (Waters e2695 Separation Module Thermo Finnigan TSQ Quantum) was adopted for qualitative analysis of sulfadiazine, sulfamerazine, sulfamethoxazole, and their products; HPLC analysis conditions were as follows: chromatographic column was $\mathrm{C} 18$ column (Thermo Basic C18, $150 \mathrm{~mm} \times 2.1 \mathrm{~mm}$ ), mobile phase was acetonitrile, and the mass fraction was $0.1 \%$ formic acid
TABLE 2: Mass spectrometric parameters in full scan mode.

\begin{tabular}{lcc}
\hline Parameter name & & Parameter values \\
\hline Electrospray voltage & & $3500 \mathrm{~V}$ \\
Sheath gas & $\mathrm{N}_{2}$ & $0.28 \mathrm{MPa}(40 \mathrm{psi})$ \\
Auxiliary gas & $\mathrm{N}_{2}$ & $0.07 \mathrm{MPa}(10 \mathrm{psi})$ \\
Ion transport capillary temperature & & $270^{\circ} \mathrm{C}$ \\
Scanning range & & $50 \sim 500 \mathrm{~m} / z$ \\
\hline
\end{tabular}

solution, using gradient elution mode. Detection time lasted for $30 \mathrm{~min}$, mobile phase flow rate was $300 \mu \mathrm{L} \cdot \mathrm{min}^{-1}$, the column temperature was $35^{\circ} \mathrm{C}$, and the injection volume was $10 \mu \mathrm{L}$. 
TABLE 3: Effect of $\mathrm{Fe}^{3+}$ on ultrasonic degradation of sulfa antibiotics.

\begin{tabular}{|c|c|c|c|c|c|c|}
\hline \multirow{2}{*}{ Substance name } & \multirow{2}{*}{$\mathrm{pH}$} & \multicolumn{2}{|c|}{ Ultrasound } & \multirow[b]{2}{*}{$\mathrm{Fe}^{3+}$ dosage $/ \mathrm{mmol} \cdot \mathrm{L}^{-1}$} & \multicolumn{2}{|l|}{$\mathrm{Fe}^{3+}$-Ultrasound } \\
\hline & & $k / \mathrm{L} \cdot \mathrm{mmol}^{-1} \cdot \min ^{-1}$ & $R^{2}$ & & $k / \mathrm{L} \cdot \mathrm{mmol}^{-1} \cdot \min ^{-1}$ & $R^{2}$ \\
\hline \multirow{3}{*}{ Sulfadiazine } & 7 & 5.6666 & 0.9992 & 0.05 & 6.2572 & 0.9954 \\
\hline & 8 & 6.9630 & 0.9922 & 0.05 & 7.6543 & 0.9882 \\
\hline & 9 & 8.2422 & 0.9906 & 0.05 & 9.7026 & 0.9623 \\
\hline \multirow{3}{*}{ Sulfamerazine } & 7 & 7.8615 & 0.9961 & 0.05 & 9.3386 & 0.9810 \\
\hline & 8 & 8.2518 & 0.9913 & 0.05 & 10.371 & 0.9744 \\
\hline & 9 & 9.9267 & 0.9874 & 0.05 & 11.886 & 0.9628 \\
\hline \multirow{9}{*}{ Sulfamethoxazole } & 7 & 6.7640 & 0.9930 & 0.05 & 7.1840 & 0.9899 \\
\hline & 8 & 7.8218 & 0.9901 & 0.05 & 8.4047 & 0.9801 \\
\hline & 9 & 9.8719 & 0.9910 & 0.05 & 12.358 & 0.9817 \\
\hline & 7 & 6.7640 & 0.9930 & 0.10 & 7.3010 & 0.9819 \\
\hline & 8 & 7.8218 & 0.9901 & 0.10 & 9.0281 & 0.9814 \\
\hline & 9 & 9.8719 & 0.9910 & 0.10 & 14.884 & 0.9647 \\
\hline & 7 & 6.7640 & 0.9930 & 0.20 & 7.2641 & 0.9922 \\
\hline & 8 & 7.8218 & 0.9901 & 0.20 & 8.4559 & 0.9781 \\
\hline & 9 & 9.8719 & 0.9910 & 0.20 & 13.590 & 0.9822 \\
\hline
\end{tabular}

MS conditions were as follows: full scan mode was employed for analysis of sulfadiazine, sulfamerazine, sulfamethoxazole, and their products; MS spectrometry ionization source was heating type electrospray ionization source (H-ESI), with specific parameters shown in Table 2.

These three sulfa antibiotics could be separated and peaked well in this full scale mode; the peak time of sulfadiazine, sulfamerazine, and sulfamethoxazole was $3.05 \mathrm{~min}$, $4.87 \mathrm{~min}$, and $13.13 \mathrm{~min}$, respectively.

\section{Results and Analysis}

3.1. $\mathrm{Fe}(V I)-U S$ Synergy. The initial concentrations of sulfadiazine, sulfamerazine, and sulfamethoxazole were all $0.02 \mathrm{mmol} \cdot \mathrm{L}^{-1}$, the ultrasonic frequency was $800 \mathrm{kHz}$, the output electric power was $100 \mathrm{~W}$, reaction $\mathrm{pH}$ was controlled ranging from 7 to 9 , and $0.05 \mathrm{mmol} \cdot \mathrm{L}^{-1}$ of potassium ferrate was added to the reaction solution, studying the removal effect of sulfa antibiotics by Fe(VI)-US. Figure 2 presented the removal effect of sulfa antibiotics by ultrasound (US), potassium ferrate $(\mathrm{Fe}(\mathrm{VI})$ ), and potassium ferrate-ultrasound (Fe(VI)-US), respectively, at different $\mathrm{pH}$ values at the reaction time of $10 \mathrm{~min}$; results showed that, compared with the degradation by US or Fe(VI) alone, Fe(VI)-US had a significant role in promoting degradation of sulfa antibiotics. It was demonstrated that ultrasonic irradiation had a good effect for degradation of oxidation of sulfadiazine, sulfamerazine, and sulfamethoxazole, and the common oxidation of ultrasonic irradiation and potassium ferrate greatly increased the removal rate of sulfa antibiotics, which might be one of the reasons why $\mathrm{Fe}(\mathrm{VI})-\mathrm{US}$ technology had synergistic effect.

3.1.1. Promotion Effect of $\mathrm{Fe}^{3+}$. In the process of oxidizing sulfa antibiotics by potassium ferrate, $\mathrm{Fe}(\mathrm{VI})$ turned to Fe(III) finally; the other reason why Fe(VI)-US had synergy might be that the existence of $\mathrm{Fe}$ (III) promoted the degradation of sulfa antibiotics. $\mathrm{Fe}^{3+}$ was added into reaction solution, studying the effect of $\mathrm{Fe}^{3+}$ on degradation of sulfa antibiotics by ultrasonic irradiation, as shown in Table 3. According to the experimental data, $\mathrm{Fe}^{3+}$ had a promoted effect on degradation of sulfa antibiotics by ultrasonic irradiation at the $\mathrm{pH}$ of 7-9. The reaction rate increased continuously and the removal effect was obvious with $\mathrm{Fe}^{3+}$ dosage increasing from $0.00 \mathrm{mmol} \cdot \mathrm{L}^{-1}$ to $0.10 \mathrm{mmol} \cdot \mathrm{L}^{-1}$. However, this promotion decreased slightly when $\mathrm{Fe}^{3+}$ dosage reached up to $0.20 \mathrm{mmol} \cdot \mathrm{L}^{-1}$.

There might be two reasons for $\mathrm{Fe}^{3+}$ promoting on degradation of sulfa antibiotics by ultrasonic irradiation. First, the addition of $\mathrm{Fe}^{3+}$ increases the ionic strength. Studies [16] have shown that, with the increase of ionic strength, more and more water molecules tend to be combined with anion and cation forming hydration film, making water molecules dissolving organic matters reduced, which results in decrease of the solubility of organic matters in water, more advantageous to head toward the cavitation bubble of gas-liquid interface migration in ultrasonic field. Cavitation bubble of gas-liquid interface is the active center of ultrasonic chemical reaction, with the presence of high concentrations of hydroxyl radicals and supercritical water layer in this region [17]; thus, it is more conducive for reaction. However, with the increase of ionic strength in water, the saturated vapor pressure of water decreases, while the surface tension increases, causing the sound pressure for cavitation increasing; the number of cavitation bubbles formed within a unit time decreases, cavitation weakens, and the removal effect lowers.

Second, the water molecules under ultrasonic cavitation will enter cavitation bubble then to form $\cdot \mathrm{OH}$ and $\cdot \mathrm{H}$ via internal thermal cracking. A lot of $\cdot \mathrm{OH}$ quickly recombine and 


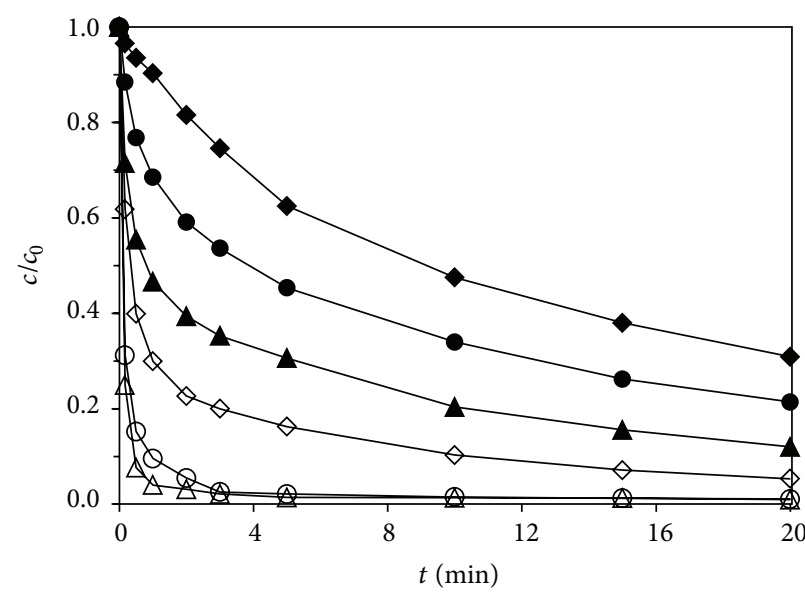

(a)

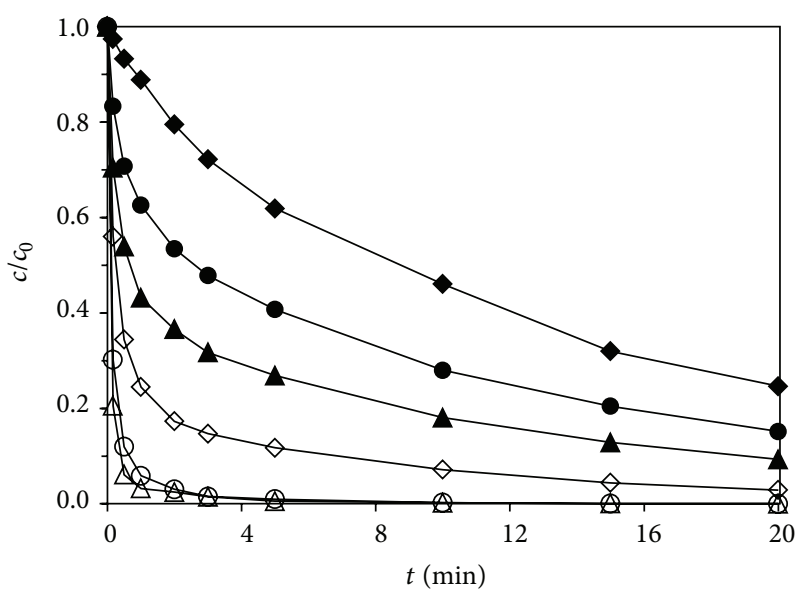

(b)

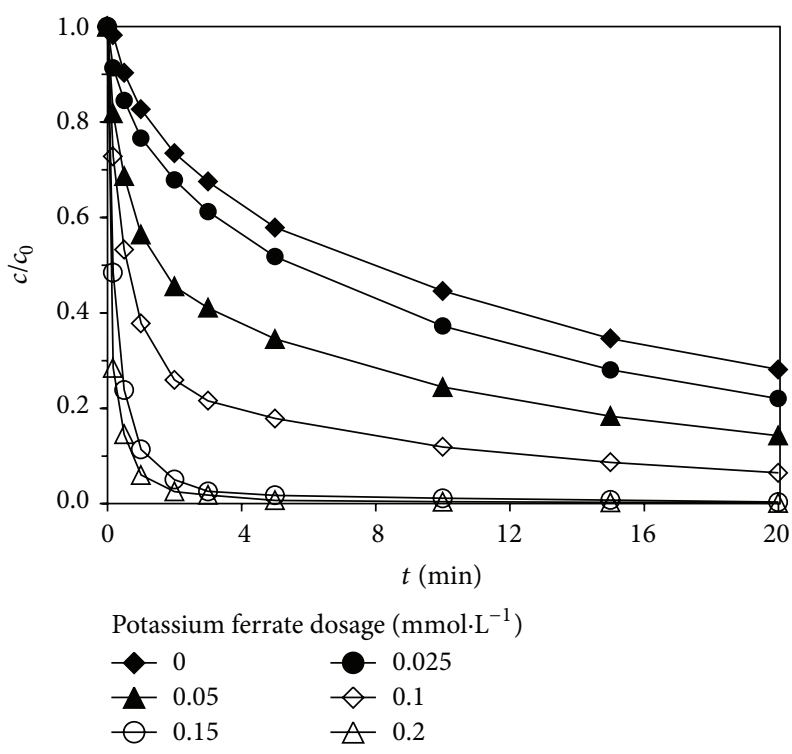

(c)

FIGURE 4: Effect of potassium ferrate dosages on degradation of sulfa antibiotics by Fe(VI)-US: (a) sulfadiazine; (b) sulfamerazine; (c) sulfamethoxazole.

generate $\mathrm{H}_{2} \mathrm{O}_{2}$ at a relatively low temperature of cavitation bubbles of gas-liquid interface; $\mathrm{H}_{2} \mathrm{O}_{2}$ eventually spreads into the main body solution and performs class Fenton reaction with $\mathrm{Fe}^{3+}((3)$ and (4)) to generate more $\cdot \mathrm{OH}$, thus promoting the removal of sulfa antibiotics as follows:

$$
\begin{aligned}
& \mathrm{Fe}^{3+}+\mathrm{H}_{2} \mathrm{O}_{2} \longrightarrow \mathrm{Fe}^{2+}+\mathrm{HO}_{2} \cdot+\mathrm{H}^{+} \\
& \mathrm{HO}_{2} \cdot+\mathrm{H}_{2} \mathrm{O}_{2} \longrightarrow \mathrm{O}_{2}+\mathrm{H}_{2} \mathrm{O}+\cdot \mathrm{OH}
\end{aligned}
$$

\subsection{Effects of Degradation of Sulfa Antibiotics by Fe(VI)-US}

3.2.1. Effect of $p H$. The $\mathrm{pH}$ of reaction solution was adjusted by buffer solution; $\mathrm{pH}$ value was ranging from 7 to 9 . The initial concentrations of sulfadiazine, sulfamerazine, and sulfamethoxazole were all $0.02 \mathrm{mmol} \cdot \mathrm{L}^{-1}$, the ultrasonic frequency was $800 \mathrm{kHz}$, the output electric power was $100 \mathrm{~W}$, reaction $\mathrm{pH}$ was controlled at $7-9$, and $0.05 \mathrm{mmol} \cdot \mathrm{L}^{-1}$ of potassium ferrate was added into the reaction solution, studying the effect of $\mathrm{pH}$ on degradation of sulfa antibiotics by $\mathrm{Fe}(\mathrm{VI})$-US. Figure 3 showed the effect of different $\mathrm{pH}$ values on degradation of sulfadiazine, sulfamerazine, and sulfamethoxazole by $\mathrm{Fe}(\mathrm{VI})$-US.

As shown in Figure 3, the reaction rate declined with the increasing $\mathrm{pH}$ value. The degradation rate of these three sulfa antibiotics was the fastest at $\mathrm{pH} 7$, and the removal rate reached a maximum at the first $10 \mathrm{~min}$. As reaction extended, when the reaction time was $30 \mathrm{~min}$, the removal rate of all these three sulfa antibiotics reached maximum at $\mathrm{pH}$ 9. According to the study of sulfa antibiotics oxidized by potassium ferrate, oxidation rate was fast, and reaction was basically completed in the first 2 min when the $\mathrm{pH}$ was in neutral or acidic conditions. Due to the oxidation of potassium ferrate dominated at the early stage of Fe(VI)US, the effect of $\mathrm{pH}$ on degradation of sulfa antibiotics by 


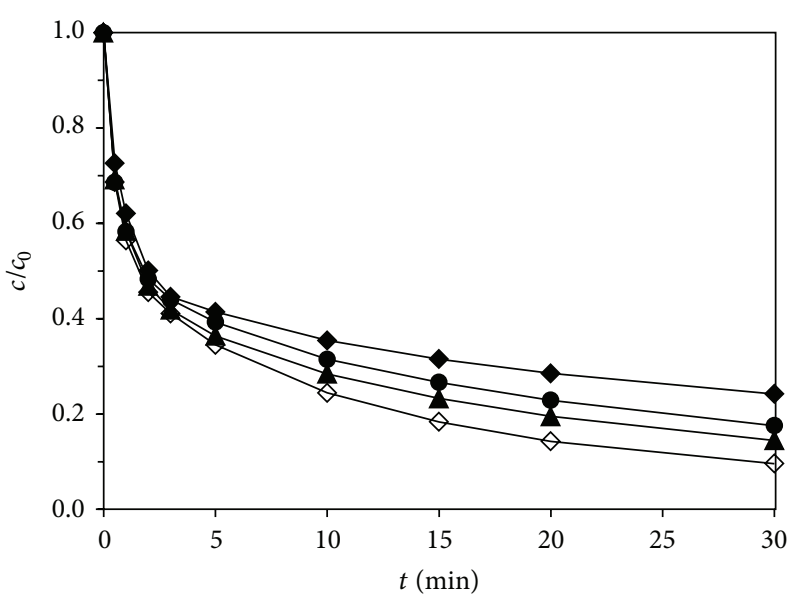

(a)

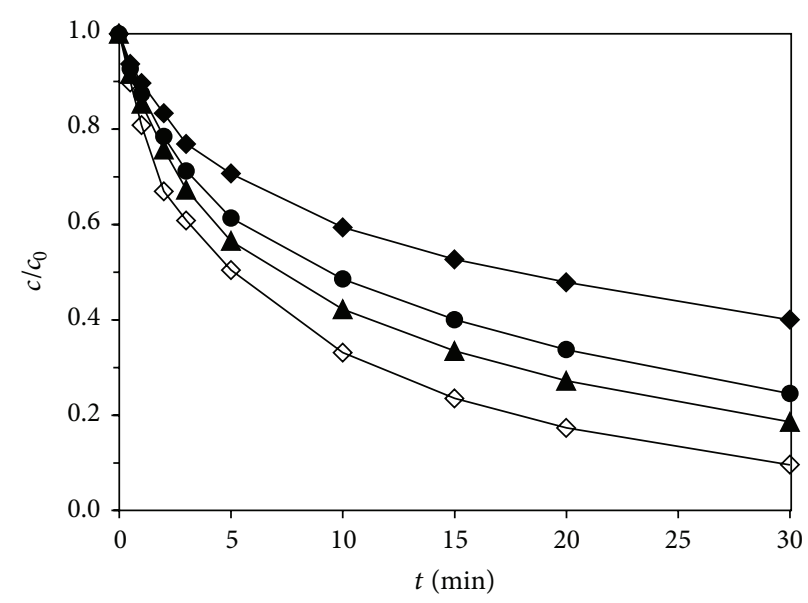

(b)

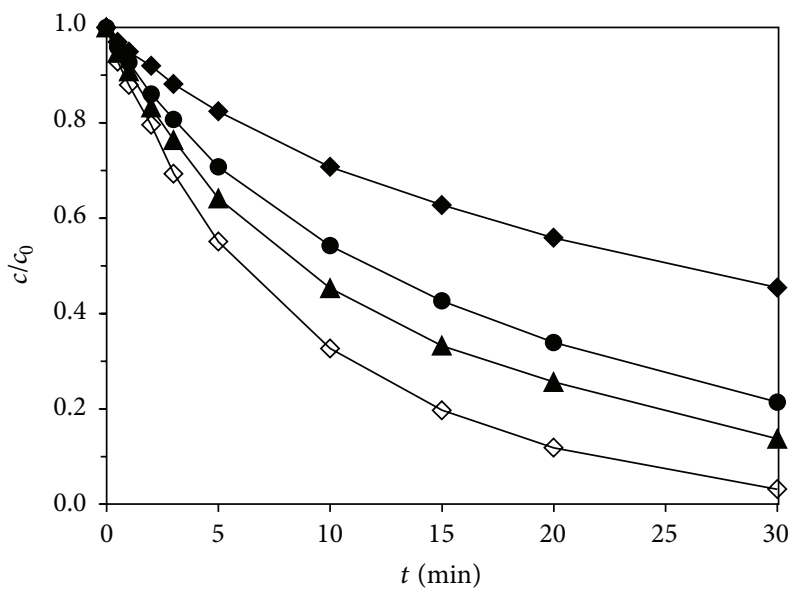

Ultrasonic frequency $(\mathrm{kHz})$

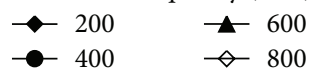

(c)

FIGURE 5: Effect of ultrasonic frequencies on degradation of sulfamethoxazole by Fe(VI)-US: (a) pH = 7; (b) pH = 8; (c) pH = 9.

$\mathrm{Fe}(\mathrm{VI})$-US was consistent with that of potassium ferrate. The oxidation of ultrasonic irradiation took leading role at the late stage; thus, the effect of $\mathrm{pH}$ was consistent with degradation of sulfa antibiotics by ultrasonic irradiation.

3.2.2. Effect of Potassium Ferrate Dosages. Different concentrations of potassium ferrate solution was added into the reaction solution, studying the effect of potassium ferrate dosages on degradation of sulfa antibiotics by Fe(VI)-US; the experimental results are shown in Figure 4.

The potassium ferrate dosages ranged from $0.00 \mathrm{mmol} \cdot \mathrm{L}^{-1}$ to $0.20 \mathrm{mmol} \cdot \mathrm{L}^{-1}$, the initial concentrations of sulfadiazine, sulfamerazine, and sulfamethoxazole were all $0.02 \mathrm{mmol} \cdot \mathrm{L}^{-1}$, the ultrasonic frequency was $800 \mathrm{kHz}$, the output electric power was $100 \mathrm{~W}$, and reaction $\mathrm{pH}$ was controlled at about 7. Figure 4 showed that potassium ferrate dosages had a significant effect on degradation of sulfa antibiotics by $\mathrm{Fe}(\mathrm{VI})$-US; with the increase of potassium ferrate dosages, the degradation rate of sulfa antibiotics by $\mathrm{Fe}(\mathrm{VI})-\mathrm{US}$ increased. When potassium ferrate dosage was $0.20 \mathrm{mmol} \cdot \mathrm{L}^{-1}$, all these three sulfa antibiotics were removed quickly, with the degradation rate reaching up to more than $98 \%$ at reaction time of $5 \mathrm{~min}$. The increase of potassium ferrate dosages enhanced the leading role of oxidation of potassium ferrate in $\mathrm{Fe}(\mathrm{VI})$-US; thus the effect of potassium ferrate dosages on degradation of sulfa antibiotics was consistent with that of oxidized by potassium ferrate.

3.2.3. Effect of Ultrasonic Frequencies. Ultrasonic frequency in experiments was 200, 400, 600, and $800 \mathrm{kHz}$, respectively, the initial concentration of sulfamethoxazole was $0.02 \mathrm{mmol} \cdot \mathrm{L}^{-1}$, and the output electric power was $100 \mathrm{~W}$, studying the effect of ultrasonic frequency on degradation of sulfa antibiotics by Fe(VI)-US. Figure 5 showed the effect of ultrasonic frequency on degradation of sulfa antibiotics by $\mathrm{Fe}(\mathrm{VI})-\mathrm{US}$ in different $\mathrm{pH}$ conditions. 


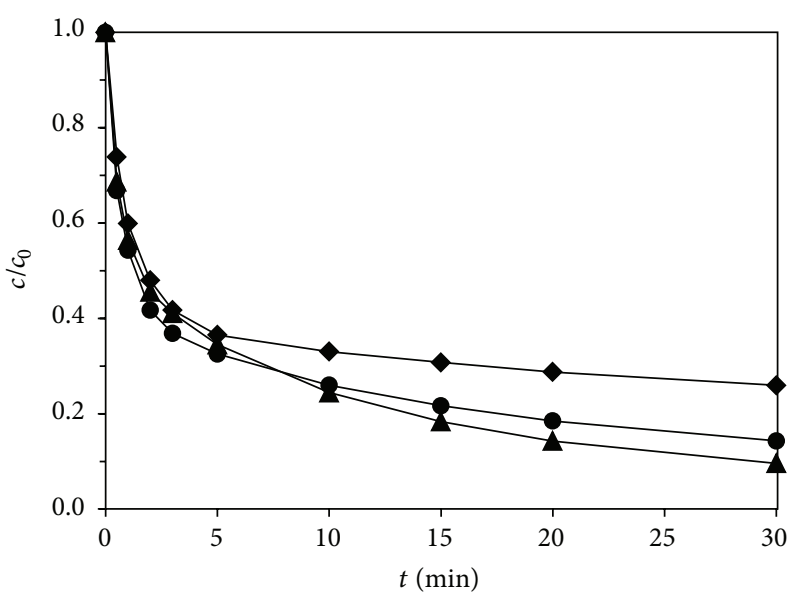

(a)

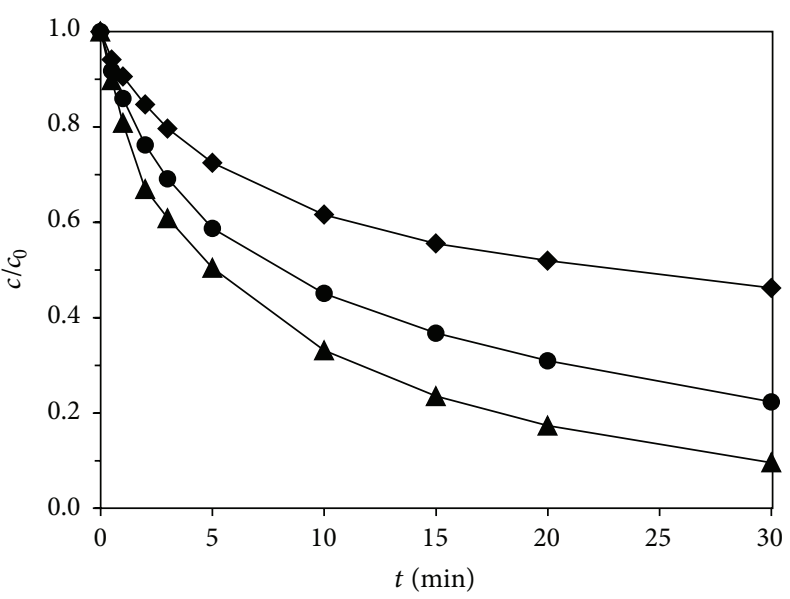

(b)

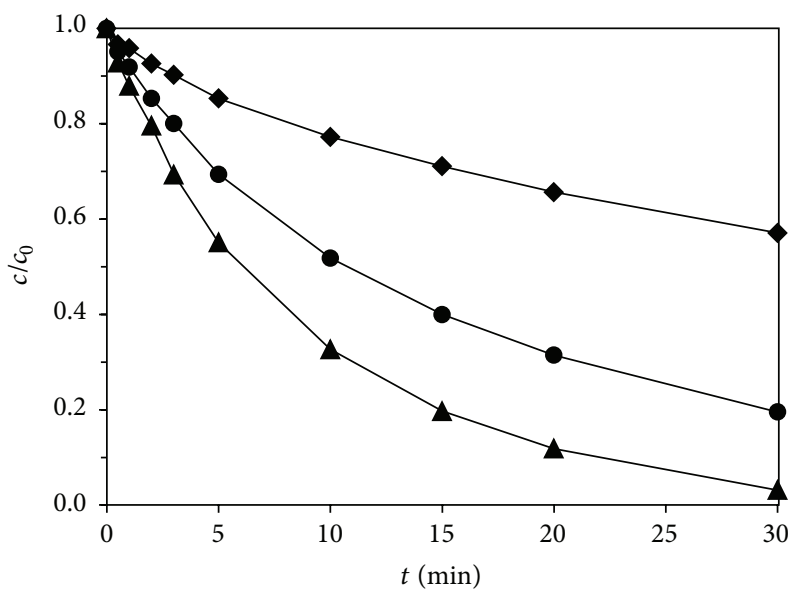

Ultrasonic power (W)

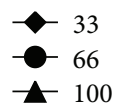

(c)

FIGURE 6: Effect of ultrasonic powers on degradation of sulfamethoxazole by $\mathrm{Fe}(\mathrm{VI})$-US: (a) $\mathrm{pH}=7$; (b) $\mathrm{pH}=8$; (c) $\mathrm{pH}=9$.

In the study of degradation of sulfa antibiotics by ultrasonic irradiation, the removal rate of sulfa antibiotics increased with the increase of ultrasonic frequency. The increase of ultrasonic frequency increased the number of hydroxyl radicals by ultrasonic cavitation and, in return, strengthens the $\mathrm{Fe}(\mathrm{VI})$-US synergy, promoting the reaction. In addition, the oxidation rate of potassium ferrate decreased as the $\mathrm{pH}$ value rose. The higher the $\mathrm{pH}$ was, the stronger $\mathrm{Fe}(\mathrm{VI})$-US the synergy was, and the amplitude of degradation of sulfa antibiotics increased with the increase of ultrasonic frequency.

3.2.4. Effect of Ultrasonic Powers. Ultrasonic power was regulated, respectively, to 33,66 , and $100 \mathrm{~W}$, studying the effect of ultrasonic powers on degradation of sulfa antibiotics by $\mathrm{Fe}(\mathrm{VI})$-US. The initial concentration of sulfamethoxazole was $0.02 \mathrm{mmol} \cdot \mathrm{L}^{-1}$, the ultrasonic frequency was $800 \mathrm{kHz}$, the effect of ultrasonic powers on degradation of sulfa antibiotics under different $\mathrm{pH}$ conditions was shown in Figure 6. According to the experimental data, the effect of ultrasonic powers on degradation of sulfa antibiotics by $\mathrm{Fe}(\mathrm{VI})-\mathrm{US}$ was consistent with that of ultrasonic frequency, and the degradation rate of sulfamethoxazole increased with the increase of ultrasonic powers. Moreover, the degradation rate increased more obviously at higher $\mathrm{pH}$ values.

The number of cavitation bubbles produced increased per unit with the increase of ultrasonic powers, so did the cavitation effect, and the $\mathrm{Fe}(\mathrm{VI})$-US synergy was enhanced at the same time. Oxidation rate of potassium ferrate declined with the increase of $\mathrm{pH}$, and the synergy of $\mathrm{Fe}(\mathrm{VI})$-US was more obvious with higher $\mathrm{pH}$ values. The larger the ultrasonic power was, the more significant the amplitude of degradation effect was. 
TABLE 4: Main identified intermediates of sulfa antibiotics.

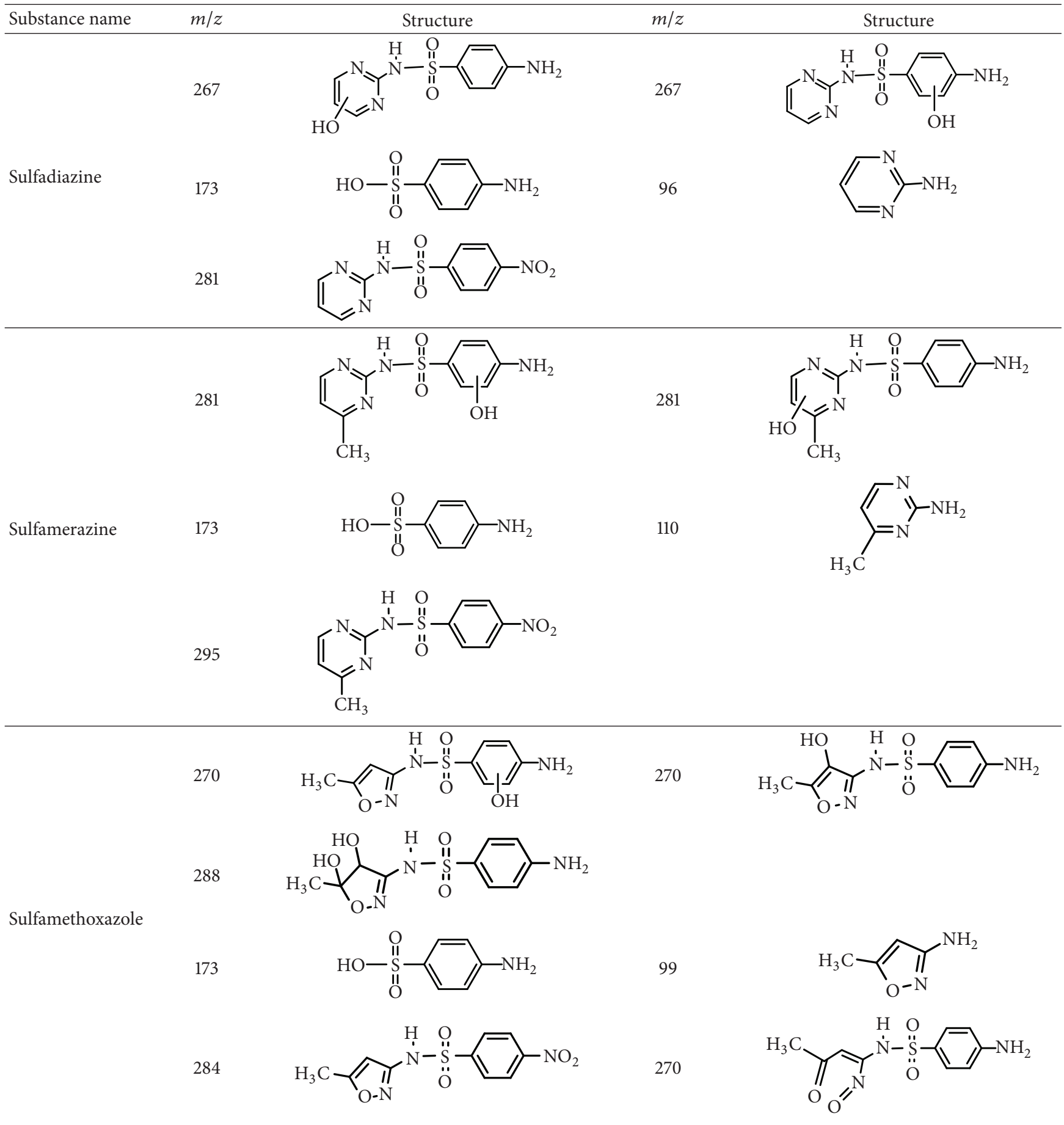

3.3. Mechanism of Degradation of Sulfa Antibiotics by Fe(VI)US. The main identified intermediates of sulfa antibiotics oxidized by $\mathrm{Fe}(\mathrm{VI})$-US were analyzed by LC-HESI-MSMS, main products of sulfadiazine, sulfamerazine, and sulfamethoxazole were listed in Table 4, and the results showing that degradation of these three sulfa antibiotics by Fe(VI)US were all removed by hydroxyl radicals with oxidation. According to the analysis of products, the degradation pathway diagram of sulfa antibiotics oxidized by Fe(VI)-US was made, and the specific degradation process was shown in Figure 7.

\section{Conclusions}

All of sulfadiazine, sulfamerazine, and sulfamethoxazole could be degraded by ultrasound well, and the reaction process was in accordance with pseudo-second order reaction kinetics. As ultrasonic irradiation time extended, the 


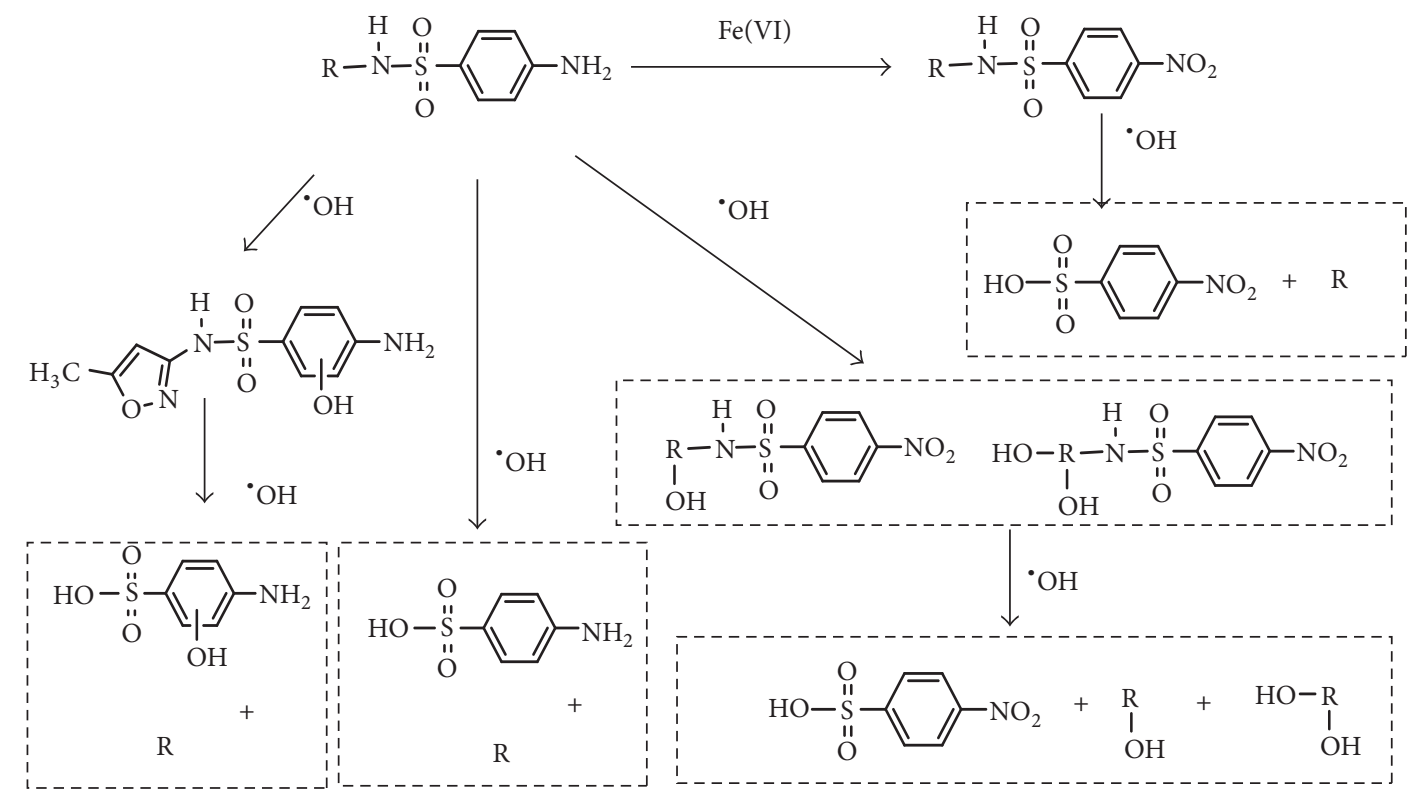

FIGURE 7: Proposed degradation pathway of sulfa antibiotics oxidized by potassium ferrate combined with ultrasound.

degradation rate of sulfa antibiotics increased continuously, and the removal rate of sulfadiazine, sulfamerazine, and sulfamethoxazole reached $77.46 \%, 82.46 \%$, and $82.46 \%$ after reaction time $30 \mathrm{~min}$, respectively.

Compared with the degradation of sulfa antibiotics oxidized by potassium ferrate or ultrasonic irradiation, $\mathrm{Fe}(\mathrm{VI})$ US technology has a significant role in promoting the degradation of sulfa antibiotics. The synergy of Fe(VI)-US mainly includes two aspects: one is the common oxidation of potassium ferrate and ultrasound, and the other is that $\mathrm{Fe}(\mathrm{VI})$ finally turns into $\mathrm{Fe}(\mathrm{III})$ in the process of degradation of sulfa antibiotics oxidized by potassium ferrate, and the existence of $\mathrm{Fe}(\mathrm{III})$ promotes the removal effect of sulfa antibiotics by ultrasound.

Degradation of sulfa antibiotics by $\mathrm{Fe}(\mathrm{VI})$-US are influenced by different sulfa antibiotics, $\mathrm{pH}$ values, potassium ferrate dosages, ultrasonic frequencies, and ultrasonic powers, and orthogonal experiments are performed to study the above five factors on degradation of sulfa antibiotics and the influence of primary and secondary order of reaction rate. The effects of $\mathrm{pH}$ values, potassium ferrate dosages, and sulfa antibiotics type on the reaction rate are the most significant, with the $\mathrm{pH}$ values being the maximum. Thus, $\mathrm{pH}$ values and sulfa antibiotics dosages should be controlled reasonably in experiments in order to ensure economy while achieving optimal removal effect.

\section{Conflict of Interests}

The authors declare that there is no conflict of interests regarding the publication of this paper.

\section{Acknowledgments}

This project was supported jointly by National Natural Science Foundation of China (51208456); The National Major
Science and Technology Project of China (2012ZX07403001, 2012ZX07403-003); and Foundation of Zhejiang Leading Team of Science and Technology Innovation (2010R50037).

\section{References}

[1] M. S. Diaz-Cruz, M. J. Garcia-Galan, and D. Barcelo, "Highly sensitive simultaneous determination of sulfonamide antibiotics and one metabolite in environmental waters by liquid chromatography-quadrupole linear ion trap-mass spectrometry," Journal of Chromatography A, vol. 1193, no. 1-2, pp. 50-59, 2008.

[2] A. J. Watkinson, E. J. Murby, and S. D. Costanzo, "Removal of antibiotics in conventional and advanced wastewater treatment: implications for environmental discharge and wastewater recycling," Water Research, vol. 41, no. 18, pp. 4164-4176, 2007.

[3] D. W. Kolpin, E. T. Furlong, M. T. Meyer et al., "Pharmaceuticals, hormones, and other organic wastewater contaminants in U.S. streams, 1999-2000: a national reconnaissance," Environmental Science and Technology, vol. 36, no. 6, pp. 1202-1211, 2002.

[4] O. A. Arikan, C. Rice, and E. Codling, "Occurrence of antibiotics and hormones in a major agricultural watershed," Desalination, vol. 226, no. 1-3, pp. 121-133, 2008.

[5] R. Hirsch, T. Ternes, K. Haberer, and K. L. Kratz, "Occurrence of antibiotics in the aquatic environment," The Science of the Total Environment, vol. 225, no. 1-2, pp. 109-118, 1999.

[6] H. Liu, G. P. Zhang, and C. Q. Liu, "Guiyang reservoir fish areas and urban sewage antibiotics feature," Bulletin of Mineralogy, Petrology and Geochemistry, vol. 26, no. Z1, p. 561, 2007.

[7] Y. P. Tai, X. D. Luo, and C. H. Mo, "Research of Guangdong province livestock feces quinolone classes and sulfa antibiotics content and distribution characteristics," Environmental Science, vol. 32, no. 4, pp. 1188-1193, 2011.

[8] M. J. Benotti, R. A. Trenholm, B. J. Vanderford, J. C. Holady, B. D. Stanford, and S. A. Snyder, "Pharmaceuticals and endocrine 
disrupting compounds in U.S. drinking water," Environmental Science \& Technology, vol. 43, no. 3, pp. 597-603, 2009.

[9] W. H. Li, Y. L. Shi, L. H. Gao, J. M. Liu, and Y. Q. Cai, "Occurrence of antibiotics in water, sediments, aquatic plants, and animals from Baiyangdian Lake in North China," Chemosphere, vol. 89, no. 11, pp. 1307-1315, 2012.

[10] W. H. Xu, Distribution, Behavior and Fate of Typical Antibiotics in the Pearl River Water, Guangzhou Institute of Geochemistry, CAS, Guangzhou, China, 2007.

[11] R. H. Wood, "The heat, free energy and entropy of the ferrate(VI) ion," Journal of the American Chemical Society, vol. 80, no. 9, pp. 2038-2041, 1958.

[12] J.-Q. Jiang and B. Lloyd, "Progress in the development and use of ferrate(VI) salt as an oxidant and coagulant for water and wastewater treatment," Water Research, vol. 36, no. 6, pp. 13971408, 2002.

[13] Y. C. Liu, H. K. Hu, M. X. Luo, and J. L. Xie, "Determination of disodium ferrate by spectrophotometry," Chemical Research and Application, vol. 14, no. 3, pp. 299-301, 2002.

[14] H. Huang, D. Sommerfeld, B. C. Dunn, E. M. Eyring, and C. R. Lloyd, "Ferrate(VI) oxidation of aqueous phenol: kinetics and mechanism," Journal of Physical Chemistry A, vol. 105, no. 14, pp. 3536-3541, 2001.

[15] B. H. J. Bielski and M. J. Thomas, "Studies of hypervalent iron in aqueous solutions. 1. Radiation-induced reduction of iron(VI) to iron(V) by CO2-," Journal of the American Chemical Society, vol. 109, no. 25, pp. 7761-7764, 1987.

[16] M. R. Hoffmann, I. Hua, and R. Höchemer, "Application of ultrasonic irradiation for the degradation of chemical contaminants in water," Ultrasonics Sonochemistry, vol. 3, no. 3, pp. 163172, 1996.

[17] E. Manousaki, E. Psillakis, N. Kalogerakis, and D. Mantzavinos, "Degradation of sodium dodecylbenzene sulfonate in water by ultrasonic irradiation," Water Research, vol. 38, no. 17, pp. 37513759, 2004. 



\section{Hindawi}

Submit your manuscripts at

http://www.hindawi.com
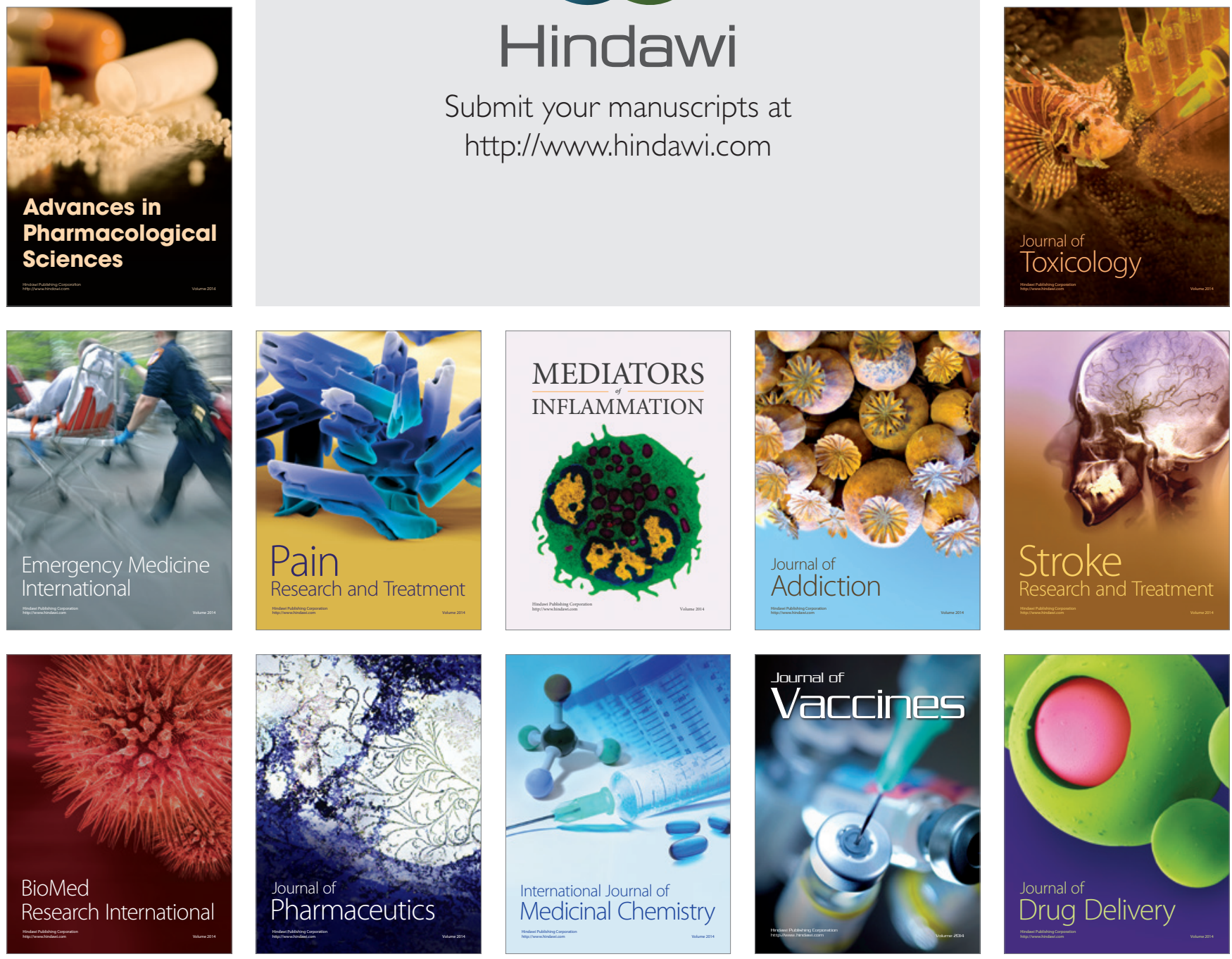